\title{
Practical use of the rising plate meter (RPM) on New Zealand dairy farms
}

\author{
J.A. LILE, M.B. BLACKWELL, N.A. THOMSON, J.W. PENNO, K.A. MACDONALD, \\ P.K. NICHOLAS, J.A.S. LANCASTER and M. COULTER \\ Dexcel, Private Bag 3123, Hamilton \\ julia.lile@dexcel.co.nz
}

\begin{abstract}
Herbage mass and rising plate meter (RPM) height was estimated using the RPM as part of a farmlet trial, at No. 2 Dairy, Dexcel Hamilton. Herbage mass estimations were collected over a 3-year period, from pre- and post-grazing and weekly farm walk estimates. The aim of the study was to determine how appropriate the RPM was for use on New Zealand dairy farms. The RPM gives reliable information using 50 readings per paddock for paddock selection, grazing residual, and average herbage mass between 1000 and $4000 \mathrm{~kg}$ $\mathrm{DM} / \mathrm{ha}$. There was a tendency however, for the RPM to underestimate herbage mass when compared with visual estimates. The RPM is limited in its estimation of herbage mass above $4000 \mathrm{~kg} \mathrm{DM} / \mathrm{ha}$ and cannot be relied upon to give useful results for dry matter intake and net herbage accumulation (particularly with weekly farm walk data). As long as RPM limits are observed, overall results show that the RPM is an inexpensive tool to aid in farm monitoring and decision making.
\end{abstract}

Keywords: dairy farming, grazing residual, herbage mass, rising plate meter, RPM height

\section{Introduction}

Herbage mass expressed as $\mathrm{kg} \mathrm{DM} / \mathrm{ha}$ is the recommended term for describing the amount of pasture in a paddock (Thomson 1986). Herbage mass can be measured directly by cutting, though this is labour intensive and often costly (Thomson 1983) and impractical in a whole farm situation. Choice of a method for herbage mass estimation should be based more on factors such as cost, convenience and personal preference rather than differences between methods in accuracy (L'Huillier \& Thomson 1988). The rising plate meter (RPM) can be used to estimate herbage mass. This method is relatively inexpensive when compared with cutting and drying. The RPM provides some objectivity in herbage mass estimation, and its use ensures people walk their farm at regular intervals. Simple monitoring systems can provide farmers with the information and confidence to make the changes necessary to increase production (Watters 1990).
Acceptance of the RPM on New Zealand dairy farms is varied, primarily owing to the time required and perceived inaccuracy associated with the many calibration procedures available to convert RPM readings to herbage mass. In addition, operator variability, paddock contour and degree of treading damage all influence how accurately the RPM estimates herbage mass. Debates are frequent on how appropriate the industry standard equations are for different regions and pasture types across the country. Thomson \& Blackwell (1999) indicated that no regional effect between the RPM and herbage mass was evident, on ryegrass-white clover summer dry environments. They did emphasise that marked variation occurred at different times of the year. Often the response to accuracy problems was to increase the number of samples per paddock, the number of paddocks assessed, or the frequency of assessment. Thomson \& Blackwell (1999) suggested targets for grazing residual are better expressed in terms of height as measured with the RPM, thus eliminating some of the variability associated with herbage mass at different times of the year.

The objective of this paper is to identify how to best use the RPM on New Zealand dairy farms. It will examine the implications on-farm to the use of RPM height and herbage mass (as estimated by the RPM) for paddock selection, grazing residual, average herbage mass, dry matter intake (DMI), and net herbage accumulation.

\section{Method}

Data were collected as part of two, 3-year farm systems trials at the No. 2 Dairy, Dexcel Limited. There were 14 herds (farmlets) in total, with a range of stocking rates, and therefore grazing intensity. Each herd was stocked with Holstein Friesian (H-Fr) cows of mixed age. Different calving periods for several of the herds changed the pattern of feed demand over the season. Pastures were non-irrigated ryegrass (Lolium perenne) and white clover (Trifolium repens). Herds 1 to 5 were managed using No. 2 Dairy's decision rules (Macdonald $\&$ Penno 1998) and herds 6 to 10 were managed using a computer simulation model UDDER (Larcombe 1994). Herds 11 to 14 were seasonal herds calving at different times of the year (also managed under the No. 2 Dairy's decision rules). 
A total of 218 paddocks were measured at approximately weekly intervals over 3 years from August 1998 to May 2001. Herbage mass was estimated, by one operator, using the RPM for all paddock events (pre- and post-grazing, conservation and topping). In addition, herbage mass was estimated using both the RPM and visual assessment during weekly farm walks. Usually no more than four people participated in the weekly farm walk, (visually estimating herbage mass with scores averaged, and using the RPM). Both the RPM and visual assessments were calibrated each week using eleven $0.3 \mathrm{~m}^{2}$ quadrats cut as close as possible to ground level with a motorised sheep shearing handpiece, washed, oven dried for 48 hours at $95-100^{\circ} \mathrm{C}$, and weighed. The RPM used was the Farm Tracker electronic rising plate meter marketed by FarmWorks ${ }^{\mathrm{TM}}$.

\section{Results and discussion}

\section{Paddock selection}

Paddock selection for grazing at No. 2 Dairy is based on visual assessments observed during the weekly farm walk. In this study, a comparison was made using three farmlets with grazing intervals from 20-33 days. The RPM height and herbage mass (measured by the RPM) estimates were compared with the actual paddock selection, made from visual estimates, for 5 days. In all cases, the RPM selected the same paddocks (selected by visual estimates) for both RPM height and herbage mass. The order was slightly different, particularly for the faster grazing interval of 20 days, but was not considered significant for a 5 -day period. This indicates that the RPM can be used for paddock selection with either RPM height or herbage mass.

\section{Grazing residual}

With the introduction of seasonal equations for RPM meters in 1999, it became apparent that target grazing residuals may be better expressed in terms of compressed height or RPM height (Table 1), rather than as herbage mass.

Figure 1 shows the seasonal pattern of post-grazing residuals for lactating H-Fr cows, on one farmlet at No. 2 Dairy, stocked at 3.2 cows per hectare, expressed as both RPM height and as herbage mass. From August to December this herd grazed to the recommended levels (Macdonald \& Penno 1998). From January to April the herd grazed below target levels in the dry summer and autumn even though herbage mass was the highest for the season. Silage supplementation was required in March to sustain milk production, while residual herbage mass levels were above $2000 \mathrm{~kg} \mathrm{DM} /$ ha.
Table $₫ 1$ Published grazing residual targets for dairy cows Blackwell \& Thomson (1999).

\begin{tabular}{llc}
\hline & & RPM units \\
\hline Lactating cows & August/September & $6-8$ \\
Lactating cows & Remainder of lactation & $8-10$ \\
Dry cows & & $3-5$ \\
\hline
\end{tabular}

Figure 1 Post-grazing residual trends for lactating Holstein Friesian cows on one farmlet stocked at $3.2 \mathrm{cows} / \mathrm{ha}$, at No. 2 Dairy, 1999/2000, (RPM height - , herbage mass

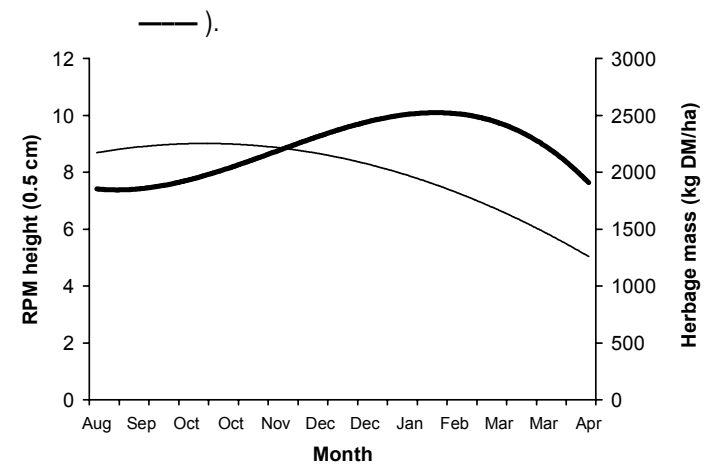

Figure $\llbracket 2$ Post-grazing residual readings as RPM height for Holstein-Friesian cows on one farmlet stocked at 3.2 cows/ha at No. 2 Dairy, 1999/2000.

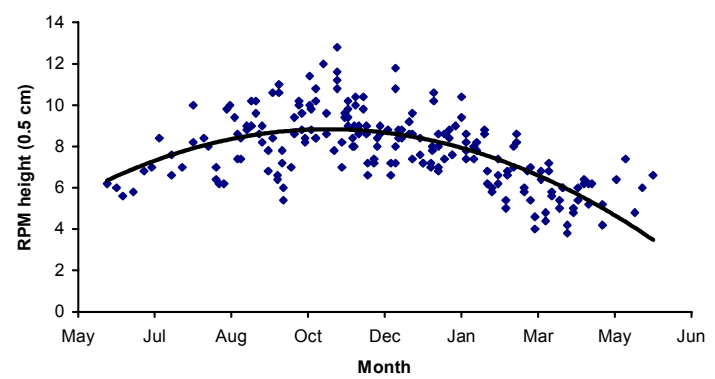

Throughout the 1999/00 season for the same farmlet stocked at 3.2 cows/ha (Figure 2), a large variation in residual grazing RPM height readings was observed.

This study indicated that the RPM can be used to measure post-grazing residual levels for both dry and lactating cows. RPM height presents a simple and universal means of expressing grazing residuals and targets. When herbage mass is used to express grazing residuals one needs to qualify this in terms of time of the year.

\section{Average herbage mass}

Overall there was a consistent pattern between the RPM and visual estimates (Figure 3). The RPM on average estimated herbage mass approximately $385 \mathrm{~kg}$ $\mathrm{DM} /$ ha below the visual estimates for the entire season. 
Figure $\llbracket 3$ Variation in average herbage mass for one paddock over a season. (Event G/S/T - G: graze, S: silage, T: topped).

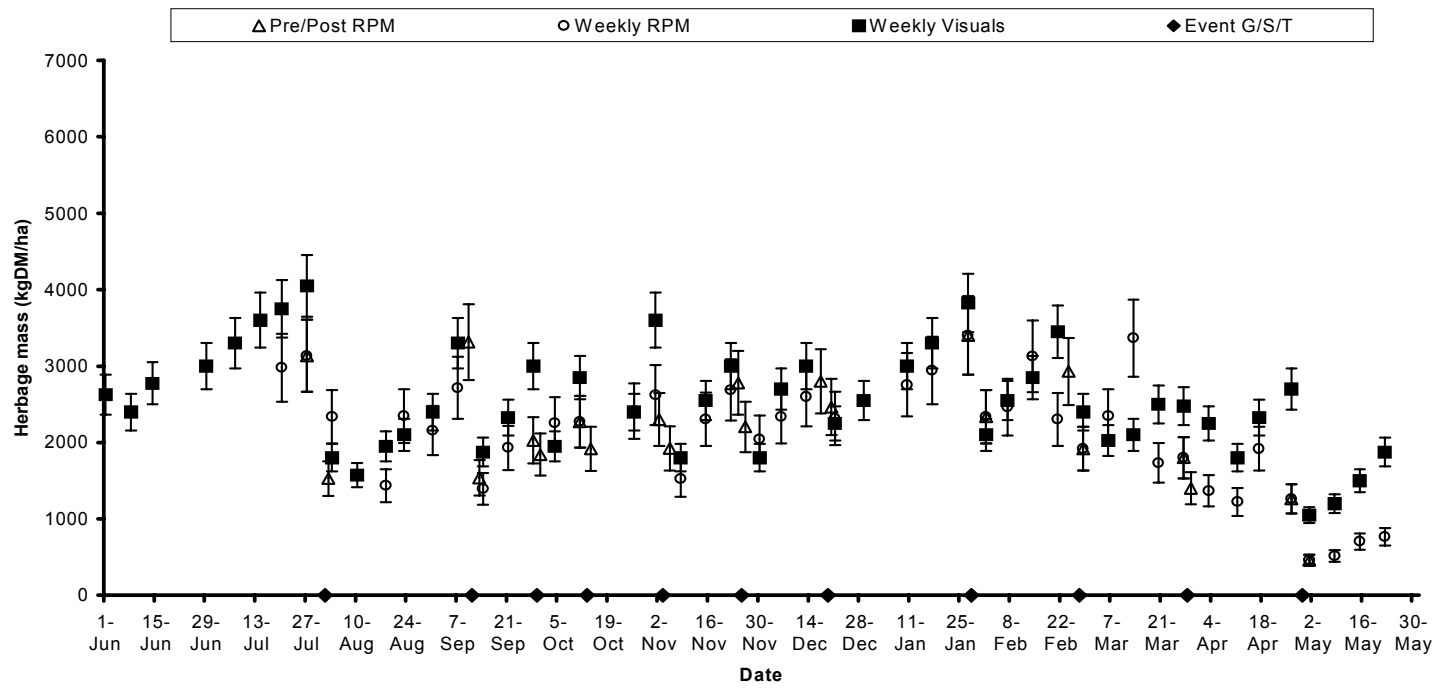

Differences between RPM and visual estimates however varied considerably, for example in April the RPM estimated $1440 \mathrm{~kg} \mathrm{DM} / \mathrm{ha}$ less and in March $1270 \mathrm{~kg}$ $\mathrm{DM} /$ ha more. There was variability over a few days between RPM estimates of up to $800 \mathrm{~kg} \mathrm{DM} / \mathrm{ha}$, observed in July. This was more evident in estimates of $3000 \mathrm{~kg} \mathrm{DM} / \mathrm{ha}$ and over. Other paddocks showed similar results. Figure 4 indicates that there was a consistent relationship between RPM and visual estimates, highlighting that the RPM has a range of approximately 1000 to $4000 \mathrm{~kg} \mathrm{DM} / \mathrm{ha}$. Estimates above $3500 \mathrm{~kg} \mathrm{DM} /$ ha were more consistent in spring than summer. During summer, levels of dead material in the pasture are variable and have been reported to affect the accuracy of herbage mass estimates irrespective of method used (Stockdale 1984). The variability in herbage mass estimates may be owing to some operator variation, and to the variable number of readings per paddock taken. This ranged from 25-50 readings per paddock. Thomson et al. (1997) indicated that $50-80$ readings per paddock should be taken to obtain the most accurate estimate of average herbage mass. L'Huillier \& Thomson (1988) mention that little difference was found between different users when correct procedures were followed.

Considering that the typical average herbage mass over a farm can range from $1500-3500 \mathrm{~kg} \mathrm{DM} /$ ha over a season, the RPM can be used to estimate average herbage mass with a reasonable level of accuracy. At least 50 readings per paddock need to be taken, and the operator must be consistent in their use of the RPM.

Walking an entire farm to obtain the average herbage mass is very time consuming, particularly on
Figure 44 RPM vs visual average herbage mass for a variety of stocking rates over a season

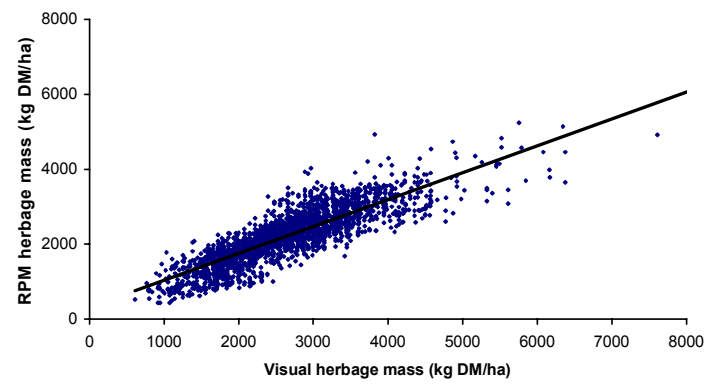

Table 2 Calculated intake from average pre- and post-grazing mass estimated using the rising plate meter for three different stocking rates $(2.2,3.2 \& 4.3$ cows/ha) at four times of the year.

\begin{tabular}{lcccc}
\hline Month & $\begin{array}{c}\text { Pre-graze } \\
\text { (kg DM/ha) }\end{array}$ & $\begin{array}{c}\text { Post-graze } \\
\text { (kg DM/ha) }\end{array}$ & $\begin{array}{c}\text { Difference } \\
\text { (kg DM/ha) }\end{array}$ & $\begin{array}{c}\text { Intake } \\
(\mathrm{kg} \mathrm{DM} / \mathrm{cow} / \mathrm{d})\end{array}$ \\
\hline June & 2637 & 1376 & 1281 & 5.3 \\
Sep & 2467 & 1968 & 500 & 4.8 \\
Jan & 3721 & 2858 & 863 & 8.0 \\
Apr & 1682 & 1436 & 246 & 3.6 \\
\hline
\end{tabular}

a large dairy farm. If only average herbage mass is required, then this may be obtained by only measuring the three highest and three lowest paddocks. Weekly RPM walk data for all paddocks, over a farmlet stocked at $3.2 \mathrm{cows} / \mathrm{ha}$ at No. 2 Dairy, showed a difference from $5 \mathrm{~kg} \mathrm{DM} / \mathrm{ha}$ up to $300 \mathrm{~kg} \mathrm{DM} / \mathrm{ha}$, when only the three highest and three lowest paddocks (out of a total of 16) were used to estimate average herbage mass (Table 3). The $300 \mathrm{~kg} \mathrm{DM} / \mathrm{ha}$ difference was only 
evident if paddocks were out for conservation, when the RPM was used to estimate over $4000 \mathrm{~kg} \mathrm{DM} / \mathrm{ha}$. Piggot (1986) found similar results where highest and lowest paddocks were within approximately $100 \mathrm{~kg}$ $\mathrm{DM} /$ ha of the correctly calculated farm cover. The more pairs of highest and lowest yielding paddocks that were grouped for averaging, the closer the average farm cover was to the mean (Piggot 1986).

Table $\llbracket 3$ Average herbage mass using the rising plate meter for all paddocks, five highest/five lowest, four highest/four lowest, and three highest/three lowest paddocks for a farmlet stocked at 3.2 cows/ha.

\begin{tabular}{lcccc}
\hline Month & $\begin{array}{c}\text { All paddocks } \\
\text { (kg DM/ha) }\end{array}$ & $\begin{array}{c}\text { five highest/ } \\
\text { five lowest } \\
\text { (kg DM/ha) }\end{array}$ & $\begin{array}{c}\text { four highest/ } \\
\text { four lowest } \\
\text { (kg DM/ha) }\end{array}$ & $\begin{array}{c}\text { three highest/ } \\
\text { three lowest } \\
\text { (kg DM/ha) }\end{array}$ \\
\hline June & 2201 & 2158 & 2149 & 2157 \\
October & 2434 & 2568 & 2615 & 2718 \\
April & 2015 & 2019 & 2018 & 2010 \\
\hline
\end{tabular}

The RPM can be used to estimate average herbage mass by using approximately three to five of the highest and lowest yielding paddocks on the farm.

\section{Dry matter intake (DMI)}

The difference between pre- and post-grazing herbage mass is often used to calculate the DMI (Thomson 1997). Table 2 shows the average DMI (estimated by the RPM) of low, medium and high stocked herds at four different times of the year. In spring, the average DMI for cows producing $23 \mathrm{~kg}$ of milk/day, at an average liveweight of $457 \mathrm{~kg}$, grazing pasture with a feed value of $13 \mathrm{MJ} \mathrm{ME} / \mathrm{kg} \mathrm{DM}$, was $4.8 \mathrm{~kg} \mathrm{DM} / \mathrm{cow} /$ day. Holmes \& Wilson (1987) suggested that a lactating $450 \mathrm{~kg}$ Friesian cow producing $0.8 \mathrm{~kg} \mathrm{MF} /$ day (milk fat) with no change in body condition, should be consuming $14 \mathrm{~kg} \mathrm{DM} /$ cow/day. Likewise, Geenty \& Rattray (1987) indicated that a lactating $450 \mathrm{~kg}$ dairy cow producing $20 \mathrm{~kg} \mathrm{FCM} /$ day (fat corrected milk), required $12 \mathrm{~kg} \mathrm{DM} /$ cow/day (at $13 \mathrm{MJ} \mathrm{ME} / \mathrm{kg} \mathrm{DM}$ ). The RPM in this instance has grossly underestimated DMI.

A study by Thomson et al. (1997) also showed a large variation in DMI when comparing visual and RPM estimates, (both calibrated and standard methods). They suggested the most reliable on-farm estimations of pasture are average farm cover and paddock ranking to determine grazing order.

As discussed in Thomson et al. (2001), it was concluded that the RPM operated differently when taking calibration plot estimates and paddock estimates. These authors suggested the RPM compressed pasture height more with paddock estimates, particularly longer pasture, causing the RPM to underestimate herbage mass. This could account for the low DMI estimate.

\section{Net herbage accumulation}

Net herbage accumulation was estimated from the weekly farm walk data for non-grazed paddocks only. Figure 5 shows a large difference in net herbage accumulation, as estimated by the RPM and visually.

The growth curves follow a similar pattern, however compared with visual estimation, the RPM is underestimating net herbage accumulation. (Visual $15449 \mathrm{~kg} \mathrm{DM} / \mathrm{ha}$, and RPM $8054 \mathrm{~kg} \mathrm{DM} / \mathrm{ha}$ ). Once again, like DMI, the level of milk production would not be supported by the low amount of net herbage accumulation the RPM is estimating. It would not be recommended that net herbage accumulation be estimated with the RPM using farm walk figures. Estimating net herbage accumulation using the RPM pre- and post-grazing data gave similar results to the weekly walk data, in that the RPM underestimated annual growth. As indicated by Thomson et al. (2001), the difference in how the RPM is placed in calibration plots and out in the paddock is the most probable cause of under estimation. In a study by Davis et al. (1998), the "difference" method (Lynch 1966) with the RPM and pasture cages was used. Net herbage accumulation estimates calculated from the monthly accumulation of herbage mass in the pasture cages using the RPM was greater than recorded by cutting pasture, and related well to dairy farm performance. To more accurately estimate net herbage accumulation using the RPM, the method used by Davis et al. (1998) is encouraged.

Figure $\llbracket 5$ Average net herbage accumulation for 14 herds during the 1999/2000 season (RPM - Visual ----).

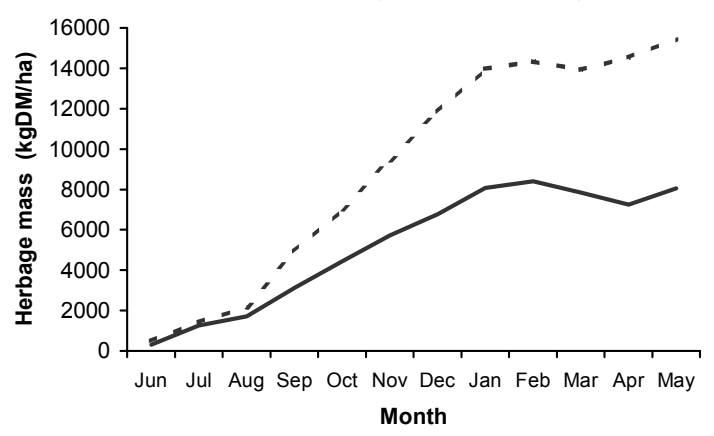

\section{Implications to on-farm use of the RPM}

The RPM provides an objective and systematic measurement system for pasture, and the seasonal RPM equations (Thomson \& Blackwell 1999) provide a means of seasonal calibration for visual assessment of herbage mass. 
Some dairy farmers take regular farm walks with the RPM and generate pasture data sometimes spanning several seasons. However, any measurement and data collection system must relate to and add value to the whole farm business (Parker 1999).

Many dairy farmers and consultants use the RPM in a variety of ways to assist their pasture monitoring, planning and decision making. Operational day to day and strategic decisions made on dairy farms that are relevant to the RPM include:

1. Paddock selection for next grazing - finding the "longest grass". The RPM can clearly assist this process, provided all "long paddocks" are measured. Anecdotal evidence from More Summer Milk farm comparison is that a technician doing a complete farm walk with the RPM, may identify different "longest paddocks" to those presumed by the farmer who has not done a farm walk. The implications of incorrect paddock selection may be most relevant in mid-spring when farmers are busiest and pasture growth is changing rapidly.

2. Allocation of pasture to meet target animal DMI e.g., break feeding. The RPM is adequate for assessing post-grazing levels in relation to targets that are best expressed in terms of RPM height. However, estimating DMI from pre- and postgrazing levels is not recommended.

3. Management of feed shortages, supplementation policy, and nitrogen applications - As with DMI, the RPM on its own will not accurately estimate the cows requirement for supplementation, especially in the summer. However, the RPM through its ability to accurately assess average herbage mass compared with required targets, can assist in planning the farms requirement for timing of nitrogen fertiliser applications, or when supplementary feeding is to commence.

4. Surplus feed identification, closing and harvesting paddocks - This requires timely and correct identification of a feed surplus or a deficit. Changes in post-grazing herbage mass, average pasture cover, and changes in the shape of the feed wedge can be measured by the RPM (given complete farm walks at regular intervals). A surplus needs to be anticipated, which depends on knowledge of expected pasture growth rates. The RPM is likely to grossly underestimate the herbage mass of very long pasture, and is therefore not recommended for estimating paddocks closed for conservation.

5. Determining stocking rate, calving date, and drying off date, in relation to annual feed supply - These decisions depend on an accurate estimate of annual herbage production, as well as the seasonal pattern of pasture growth. The RPM can estimate net herbage accumulation on ungrazed paddocks between two farm walks. However this is not recommended as it will underestimate total herbage accumulation, although it will indicate the pattern of growth. A preferred approach is to use the RPM with cages. Otherwise use published growth rate data.

6. Feed budgeting of feed supplies available, expected pasture/crop production, and feed utilisation Animal dry matter requirements are well established from research and can be used with confidence in feed budgets. Feed budgeting is to be encouraged even given the inherent error in any estimation of pastures. Monitoring what actually happens, against the feed budget, is more important than the accuracy of the original estimates. Unavailable feed (i.e., that below dry cow grazing residuals) is irrelevant to the plan. It is recommended that farmers use the winter formula $(\mathrm{x} 140+500)$ to establish the start average cover in the autumn. This effectively removes the unavailable part of herbage mass from the calculations.

\section{Conclusions}

To get the best use from the RPM for pasture assessment, the following recommendations are made:

- The RPM is suitable for paddock selection using RPM height or average herbage mass.

- The RPM can assess grazing residuals in relation to published targets and RPM height $(0.5 \mathrm{~cm})$ is the recommended way to express target grazing residuals.

- The RPM can estimate average herbage mass and will identify changes, however it will assess consistently below that of visual estimation.

- The RPM is not suitable for estimating DMI.

- The RPM is not suitable for estimating net herbage accumulation using farm walk data. More reliable data can be obtained using pasture cages.

\section{ACKNOWLEDGEMENTS}

The authors thank Dexcel No. 2 Dairy staff for collecting and Glenise Ferguson for processing pasture samples. Also Barbara Dow for statistical advice.

\section{REFERENCES}

Davis, K.L.; Thomson, N.A.; McLean, N.R.; McCallum, D.A.; Hainsworth, R.J.; Wards, A.J.; Barton, R.G. 1998. Pasture growth on dairy farms in the Golden 
Bay and the West Coast of the South Island. Proceedings of the New Zealand Grassland Association 60: 9-14.

Geenty, K.G.; Rattray, P.V. 1987. The energy requirements of grazing sheep and cattle. In: Livestock feeding on pasture. Ed. Nichol, A.M. New Zealand Society of Animal Production Occasional Publication 10: 39-53.

Holmes, C.W.; Wilson, G.F. 1987. Milk production from pasture. Butterworths of New Zealand (Ltd), Wellington.

Larcombe, M.T. 1994. UDDER 8: A Desktop Dairy Farm for Extension and Research - Operating Manual. Maffra Herd Improvement Co-op, Maffra, Vic, Australia.

L'Huillier, P.J.; Thomson, N.A. 1988. Estimation of herbage mass in rye-grass/white clover dairy pastures. Proceedings of the New Zealand Grassland Association 49: 117-122.

Lynch, P.B. 1966. Conduct of Field Experiments. Bulletin No. 399. New Zealand Department of Agriculture.

Macdonald, K.A.; Penno, J.W. 1998. Management decision rules to optimise milksolids production on dairy farms. Proceedings of the New Zealand Society of Animal Production 58: 132-135.

Parker, W.J. 1999. Farm performance measurement Linking monitoring to business strategy. Proceedings of the New Zealand Society of Animal Production 59: 6-13.

Piggot, G.J. 1986. Methods for estimating pasture dry matter on dairy farms in Northland. Proceedings of the New Zealand Grassland Association 47: 243-247.
Stockdale, C.R. 1984. Evaluation of techniques for estimating the yield of irrigated pastures intensively grazed by dairy cows. 2 . The rising plate meter. Australian Journal of Experimental Agriculture and Animal Husbandry 24: 305-311.

Thomson, N.A. 1983. Factors influencing the accuracy of herbage mass determinations with a capacitance meter. New Zealand Journal of Experimental Agriculture 11: 171-176.

Thomson, N.A. 1986. Techniques available for assessing pasture. pp.113-121. In: Dairy Farming Annual.

Thomson, N.A.; McCallum, D.A.; Howse, S.; Holmes, C.W.; Matthews, P.N.P.; Matthew, C. 1997. Estimation of dairy pastures - the need for standardisation. Proceedings of the New Zealand Grassland Association 59: 221-225.

Thomson, N.A.; Blackwell M.B. 1999. The new pasture assessment model. Proceedings of the South Island Dairy Event 1: 60-67.

Thomson, N.A.; Upsdell, M.; Hooper, R.; Henderson, H.; Blackwell, M.; McCallum, D.A.; Hainsworth, R.J.; Macdonald, K.; Wildermoth, D.; BishopHurley, G.; Penno, J. 2001. Development and evaluation of a standardised means for estimating herbage mass of dairy pastures using the rising plate meter. Proceedings of the New Zealand Grassland Association 63: 149-157.

Watters, A.F. 1990. Farm monitoring as an indicator of improved farm management practices. Proceedings of the New Zealand Grassland Association 52: 17-19. 